Original Article

\title{
Characteristics of tasks utilized for evaluation of judgment errors in the elderly
}

\author{
Yumi Sakamoto, RPT, MS ${ }^{1)^{*}}$, Yukari Ohashi, RPT, $\mathrm{PhD}^{1)}$ \\ 1) Department of Physical Therapy, School of Healthcare, Ibaraki Prefectural University of Health \\ Sciences: 4669-2 Ami, Ami-Machi, Inashiki-gun, Ibaraki 300-0394, Japan
}

\begin{abstract}
Purpose] The present study compared assessments utilized to evaluate judgment errors in the elderly. [Subjects and Methods] A total of 94 community-dwelling elderly participants in an examination of physical fitness for health promotion and health guidance in a rural area in Japan were included. Spatially and temporally predictive tasks were used to evaluate judgment errors. Distances measured on the Functional Reach and upward reaching tests were used to assess spatial prediction, and times measured on the Timed Up and Go test and Standardized Walking Obstacle Course were used to assess temporal prediction. Differences between the self-predicted values and actual results were deemed judgment errors. [Results] Significant differences were observed between selfpredicted abilities and the patients' performances. Participants underestimated their abilities in spatially predictive tasks and overestimated them in temporally predictive tasks. On comparing the four tasks, there were significant differences in judgment error ratios between them. Statistical analysis indicated a significant difference in the judgment error ratio for the Standardized Walking Obstacle Course correlated with a history of falls. [Conclusion] Judgment errors were identified using both spatially and temporally predictive tasks. A temporally predictive task like the Standardized Walking Obstacle Course might better evaluate judgment errors in the elderly. Key words: Judgment error, Spatially predictive task, Temporally predictive task
\end{abstract}

(This article was submitted Apr. 22, 2016, and was accepted Jun. 27, 2016)

\section{INTRODUCTION}

The aims of this study were to evaluate judgment errors in the elderly using different predictive tasks and to compare characteristics between the tasks utilized for evaluation. Japan has already become a super-aged society, and thus many issues related to aging have gained importance. Falls among elderly people are one of the major concerns related to aging, as falls often result in morbidity, mortality, or psychosocial trauma. Many researchers have reported a huge number of variables that increase the risk of falls ${ }^{1-8)}$. In general, it is believed that falls in the young-old are caused by external factors rather than internal factors ${ }^{3-6,8)}$.

However, falls are seldom caused by a single factor. Falls occur usually due to a combination of internal and external factors $^{3-6,8)}$. Some falls may occur because a person's self-perception of their balance ability is incorrect. Sugihara ${ }^{9)}$ noted that falls might have been avoided if a different strategy had been adopted after an appropriate assessment of internal factors. For safe daily living, it is important for individuals to adopt strategies and behaviors that are compatible with their own physical abilities. Judgment errors in an individual's assessment of their own balance ability could increase the risk of falls ${ }^{9-14)}$.

Several researchers have reported on the relationship between aging and judgment errors about physical ability and on the relationship between falls and judgment errors ${ }^{9-11,15-19)}$. In these studies, several tasks were utilized to evaluate judgment errors of physical ability in the elderly. The assessments can be roughly divided into two types: spatially predictive tasks and temporally predictive tasks ${ }^{17}$ ). The Functional Reach Test (FR) or other reaching tasks, step-over test, and maximum

\footnotetext{
*Corresponding author. Yumi Sakamoto (E-mail: sakamotoy@ipu.ac.jp)

(C)2016 The Society of Physical Therapy Science. Published by IPEC Inc.

This is an open-access article distributed under the terms of the Creative Commons Attribution Non-Commercial No Derivatives (by-nc-nd) License $<$ http://creativecommons.org/licenses/by-nc-nd/4.0/>.
} 
one stride length test are examples of spatially predictive tasks $9,10,12,17-20$ ). The Timed up and Go test (TUG), maximum gait speed, 20 step walking time, and single-leg standing are examples of temporally predictive tasks ${ }^{15-17)}$. In most spatially predictive tasks, length and distance are used as the indices, whereas the test duration is used as the index in temporally predictive tasks, as measured by the mental chronometry method.

If judgment errors about self-balance ability are an important concern for the elderly, easy and practical assessment tools are needed to evaluate them. In the present study, we examined judgment errors in community-dwelling elderly people using two spatially predictive tasks (FR and upward reach) and two temporally predictive tasks (TUG and walking on an obstacle course).

\section{SUBJECTS AND METHODS}

Eligible subjects for this study were elderly people who participated in measurements of physical fitness for health promotion and health guidance for community-dwelling elderly conducted in a rural area of Ibaraki Prefecture in Japan in fiscal year 2011. Residents who felt unwell or were medically unstable (e.g., uncontrolled high blood pressure or recent noteworthy medical diagnosis within six months before this study) were excluded from participation. There were 94 subjects aged 63 to 87 years old (mean age \pm SD: $75.5 \pm 5.8$ ), including 42 males and 52 females (mean age \pm SD: $76.1 \pm 5.9$ and 75.1 \pm 5.8 , respectively). Subjects were informed of the research purpose and procedures and voluntarily signed an informed consent before testing was initiated. All subjects were able to ambulate without assistance during the examination.

We measured the following parameters of physical function of the elderly: 1) grip strength, 2) score of trunk flexion in a long sitting position, 3) duration of a single-leg standing test with open/closed eyes, 4) score of the FR, 5) time of the TUG, 6) comfortable and maximum gait speeds, 7) time on the Standardized Walking Obstacle Course (SWOC), and 8) upward reach (UR) height. The grip strength, score of trunk flexion in the long sitting position, duration of the single-leg standing test with open/closed eyes, score of the $\mathrm{FR}^{21)}$, and time of the $\mathrm{TUG}^{22)}$ were measured by the standardized methods.

To measure the comfortable and maximum gait speeds, we asked subjects to walk $11 \mathrm{~m}$ (consisting of $3 \mathrm{~m}$ of acceleration, $5 \mathrm{~m}$ of the actual test distance, and $3 \mathrm{~m}$ of deceleration) at two different gait speeds, a comfortable speed and their maximum speed. The gait speeds were calculated using the test distance and walking time measured in the actual test zone.

In order to evaluate balance and ambulation in a way that approximated activities of daily living (ADL), we utilized the SWOC, which consists of a $12.2 \mathrm{~m}$ long and $0.92 \mathrm{~m}$ wide path with three directional changes ${ }^{23}$. Along the SWOC course, there were obstacles including an axillary crutch, a kitchen-size trash can, a section of shower curtain with a "busy pattern," a black heavy pile shag rug, a chair with arms, and a chair without arms. We asked the subjects to rise from a chair, walk along the course while avoiding the obstacles, and sit down on a chair placed on the other side of the course. The ambulation time through the SWOC was measured in seconds.

In ADL, we often need to reach a hand in an upward direction when getting something down from a rack. We placed a stadiometer on a table $(41 \mathrm{~cm}$ high) and put a small light empty plastic cup on the head plate of the stadiometer. The subjects were positioned in front of the table $(10 \mathrm{~cm}$ apart) with their feet naturally apart and were asked to reach their hand upward as far as possible, without stepping out of their initial base of support, to lift the plastic cup off the head plate of the stadiometer. The highest distance the subject was able to lift the cup off the head plate without stepping out of their initial base of support was used as the index of UR.

Prior to completing the FR, UR, TUG, and SWOC, we explained each procedure to the subjects and asked them to visualize the task and to estimate their capability of performing each task; in this way, we determined predictive variables for self-awareness before they executed each task.

To predict their own performance on the FR and UR, the subjects were instructed to visually estimate the location where they would reach, according to the procedures, without losing their balance. Before they executed the tasks, they were asked to indicate the location they thought they could reach using an extendable pointer. We measured the distance between the starting positions of the subjects and the location they indicated for the FR, and we measured the height of the location they indicated for the UR. These distances were recorded as the predicted FR and predicted UR.

For the TUG and SWOC tasks, the variables of self-awareness were measured using the mental chronometry method. Before our subjects completed the TUG and SWOC, we trained them to use a stopwatch. After they learned to use a stopwatch, the subjects were positioned on a chair and were instructed about how to complete the TUG and SWOC. Then, they were asked to close their eyes and imagine themselves completing the TUG and SWOC without moving their extremities. The subjects each operated a stopwatch and measured the time it took them to visualize themselves completing the TUG and SWOC. The times they measured were recorded as the predicted TUG and predicted SWOC. For the indices of judgment error for each task, we used a formula to subtract the observed values from the predicted values, and we used the calculated values as well as the absolute values.

Based on the definition of Gibson et al. ${ }^{26,27)}$, the one-year retrospective falls incidence was obtained from an interview with each subject. In addition, we asked the subjects if they had a fear of falling.

All participants were supervised by physical therapists or trained physical therapy students during performance of the tasks to protect them from falls or other hazards during testing. Spatial data were recorded in centimeters, and temporal data were recorded in seconds. The patient interview and fall survey were completed first before execution of the various tasks. 
The predictive variables of the FR, UR, TUG, and SWOC were measured before execution of the actual measurements. Our study was approved by the ethics committee of our university.

The relationships between the predicted and observed values of the four predictive tasks were analyzed using the paired t-test. The levels of association between the judgment error variables and other variables of interest were examined using the Pearson's product-moment correlation coefficient. In addition, we divided the subjects into $60 \mathrm{~s}$, $70 \mathrm{~s}$, and $80 \mathrm{~s}$ age groups to compare age-related differences in their judgment errors using one-way ANOVA. The numbers of subjects in the 60s, 70s, and 80 s age groups were 13,53 , and 28 , respectively.

To compare the characteristics of the four predictive tasks, we utilized a judgment error ratio calculated with a formula that divided the predictive value by the observed value ${ }^{15,17}$. Differences in the judgment error ratios between the four predictive tasks were compared using repeated one-way ANOVA. We also compared the judgment error ratios of the four predictive tasks by age, presence or absence of falls in the last year, fear of falling, and the risk of frailty using repeated two-way ANOVA. For age, we divided the subjects into two groups, age $<75$ and age $\geq 75$. We used grip strength to assess the risk of frailty in the subjects; male subjects were deemed at risk of frailty if their grip strength was under $26 \mathrm{~kg}$, and female subjects were deemed at risk of frailty if their threshold was under $18 \mathrm{~kg}$.

All statistical analyses were performed using IBM SPSS Statistics for Windows version 21.0 (IBM Corp.). Test statistics were considered significantly different or related at an alpha level of 0.05 .

\section{RESULTS}

Table 1 shows the descriptive statistics for the measured variables. All results are mean \pm SD values unless otherwise noted. According to our interviews and fall survey, 18.1\% of subjects (17 out of 94 ) had experienced falls during the past year, and $19.1 \%$ of subjects (18 out of 94 ) had a fear of falling.

Statistical analysis demonstrated that age was correlated with all of the measured variables except the height of UR. Grip strength $(r=-0.303, \mathrm{p}=0.003)$, score of trunk flexion in the long sitting position $(r=-0.215, \mathrm{p}=0.037)$, duration of the single-leg standing test with open eyes $(r=-0.264, \mathrm{p}=0.01)$ or closed eyes $(r=-0.350, \mathrm{p}=0.001)$, score of the FR $(r=-0.318, \mathrm{p}=0.002)$, comfortable gait speed $(r=-0.343, \mathrm{p}=0.001)$, and maximum gait speed $(r=-0.402, \mathrm{p}<0.001)$ all decreased with age, and the times needed to complete the TUG and SWOC increased with age $(r=0.387, \mathrm{p}<0.001 ; r=0.354, \mathrm{p}<0.001$, respectively). However, there were no correlations between age and judgment errors and absolute judgment errors for the four predictive tasks. When we compared the judgment errors and absolute judgment errors of the four predictive tasks among the three age groups, we found significant differences between the groups in the absolute judgment error for the $\operatorname{SWOC}\left(F_{(2,93)}=4.086\right.$, $\mathrm{p}=0.02$ ). The mean absolute judgment error and standard deviation for the SWOC in the $60 \mathrm{~s}, 70 \mathrm{~s}$, and $80 \mathrm{~s}$ age groups were $2.07 \pm 1.56,3.23 \pm 2.31$, and $4.33 \pm 2.96$, respectively. Multiple comparisons indicated that the absolute judgment error for the SWOC among subjects in their 80 s was significantly higher than that among subjects in their $60 \mathrm{~s}$.

Table 2 summarizes the predicted and observed values for the FR, UR, TUG, and SWOC. Although they were instructed to remain still, 36 subjects actually moved when they completed the estimation task for the FR. Therefore, we calculated the judgment error in the FR for the remaining 58 subjects. In all four of the predictive tasks, there were significant differences between the predicted and observed values; the predicted values were significantly shorter than the observed values for the FR and UR, and the predictive values were significantly lower than the observed values for the TUG and SWOC (all p-values $<0.05$ ).

Table 1. Descriptive statistics for the measured variables

\begin{tabular}{lc}
\hline & $\mathrm{N}=94$ \\
\hline Age (years) & $75.5 \pm 5.8$ \\
Height $(\mathrm{cm})$ & $154.2 \pm 8.7$ \\
Body weight $(\mathrm{kg})$ & $57.3 \pm 8.8$ \\
Grip strength $(\mathrm{kg})$ & $27.3 \pm 8.5$ \\
Trunk flexion in the long sitting position (cm) & $36.8 \pm 9.1$ \\
Single-leg standing with open eyes (s) & $24.27 \pm 26.12$ \\
Single-leg standing with closed eyes (s) & $4.59 \pm 3.98$ \\
Comfortable gait speed (m/s) & $1.25 \pm 0.24$ \\
Maximum gait speed (m/s) & $1.67 \pm 0.31$ \\
Functional Reach test (cm) & $31.0 \pm 7.0$ \\
Timed Up and Go test (s) & $8.30 \pm 1.42$ \\
SWOC score (s) & $12.13 \pm 2.50$ \\
Upward reach (cm) & $183.6 \pm 11.4$ \\
\hline
\end{tabular}

(Average \pm standard deviation)

SWOC: Standardized Walking Obstacle Course 
To compare the judgment error ratios of the four tasks, we analyzed the data of the 58 subjects who were included in the analysis of judgment error for the FR. The judgment error ratios are shown in Table 3. Repeated one-way ANOVA indicated significant differences in the judgment error ratios between the four predictive tasks $\left(F_{(3,171)}=18.034, \mathrm{p}<0.001\right)$. According to multiple comparisons, there were significant differences in the judgment error ratios between the FR and UR, FR and SWOC, UR and TUG, and TUG and SWOC (by Bonferroni method, $\mathrm{p}<0.001$ ).

Table 4 shows the association between the judgment error ratios of the four predictive tasks and the four other factors. With regard to age, history of falls in the past year, presence/absence of fear of falling, and risk of frailty, repeated two-way ANOVA indicated a significant main effect of task type $\left(F_{(3,168)}=9.721, F_{(3,168)}=17.439, F_{(3,168)}=12.955, F_{(3,168)}=7.542\right.$, respectively, all p-values $<0.001)$. However, ANOVA indicated the absence of a main effect for other factors and the absence of any significant interaction, except for history of falls in the past year. In reference to the history of falls in the past year, ANOVA indicated significant interaction effects between factors $\left(F_{(3,168)}=3.507, \mathrm{p}=0.023\right)$, and there was no significant difference with respect to the history of falls factor. Multiple comparisons indicated significant differences in the judgment error ratios for the SWOC between fallers and non-fallers $(t=3.208, \mathrm{p}=0.003)$.

\section{DISCUSSION}

The data collected from our 94 subjects are comparable to the average data for the same age group from the "Physical Fitness and Athletic Ability Survey" conducted by the Japanese Ministry of Education, Culture, Sports, Science and Technology in the same fiscal year ${ }^{28}$. Moreover, the reported yearly incidence rate for falls among elderly Japanese is $10 \%$ to $20 \%$, and the most frequently reported rate is less than $20 \%{ }^{29}$. In this study, $18.1 \%$ of the subjects had fallen in the past year, which reflected Japanese average rate.

Using spatially and temporally predictive tasks, we examined the differences between the predicted and observed performance values among community-dwelling elderly people. In this study, significant differences between predictions and observations were demonstrated in all four predictive tasks. For the temporally predictive tasks, we used the mental chronometry method, whereby the time difference between the actual physical execution of a movement and the imagined performance of the same movement was measured. Previous studies have reported that the duration of imagined movement corresponds well to the duration of the actual movement in young healthy people ${ }^{11,15,16,24,25,30)}$. In contrast, significant time differences have been reported in elderly people ${ }^{11,15,16)}$. With regard to spatially predictive tasks, similar results have been noted in prior studies ${ }^{9,12,18)}$. According to the results of other studies, it was assumed that the community-dwelling elderly in our study would show noteworthy errors of judgment, which could be confirmed by the spatial and temporal tasks utilized in the present study.

Table 2. Predicted values and observed values of the four tasks

\begin{tabular}{lccc}
\hline & $\mathrm{N}$ & Predicted & Observed \\
\hline${\text { Functional Reach test }(\mathrm{cm})^{\dagger}}^{\dagger}$ & 58 & $25.6 \pm 8.4$ & $32.0 \pm 6.8$ \\
${\text { Upward reach test }(\mathrm{cm})^{\dagger}}$ & 94 & $177.9 \pm 11.2$ & $183.5 \pm 11.3$ \\
Timed Up and Go test $(\mathrm{s})^{\dagger}$ & 94 & $6.11 \pm 2.30$ & $8.30 \pm 1.42$ \\
SWOC score $(\mathrm{s})^{\dagger}$ & 94 & $11.25 \pm 4.14$ & $12.13 \pm 2.50$ \\
\hline
\end{tabular}

SWOC: Standardized Walking Obstacle Course

$\dagger$ The paired t-test indicated significant difference between the predicted value and observed value $(\mathrm{p}<0.05)$
Table 3. Judgment error ratios $(\mathrm{N}=58)$

\begin{tabular}{|c|c|}
\hline & Judgement error ratio \\
\hline Functional Reach test & $0.803 \pm 0.029\rceil_{*}$ \\
\hline Upward reach & $0.965 \pm 0.005]^{*}$ \\
\hline Timed Up and Go test & $0.716 \pm 0.029 \sqsupset^{*}$ \\
\hline SWOC score & $\left.0.960 \pm 0.046\lrcorner^{*}\right\rfloor$ \\
\hline
\end{tabular}

Table 4. Judgment error ratios of the four predictive tasks from the perspective of other fall risk factors $\left(\mathrm{N}=58^{*}\right)$

\begin{tabular}{lcccccccc}
\hline & \multicolumn{2}{c}{ Age } & \multicolumn{2}{c}{ Fear of falling } & \multicolumn{2}{c}{ History of falls } & \multicolumn{2}{c}{ Risk of frailty } \\
\hline & $\begin{array}{c}\text { Age }<75 \\
(\mathrm{n}=23)\end{array}$ & $\begin{array}{c}\text { Age } \geq 75 \\
(\mathrm{n}=35)\end{array}$ & $\begin{array}{c}\text { Presence } \\
(\mathrm{n}=11)\end{array}$ & $\begin{array}{c}\text { Absence } \\
(\mathrm{n}=47)\end{array}$ & $\begin{array}{c}\text { Presence } \\
(\mathrm{n}=12)\end{array}$ & $\begin{array}{c}\text { Absence } \\
(\mathrm{n}=46)\end{array}$ & $\begin{array}{c}\text { Presence } \\
(\mathrm{n}=9)\end{array}$ & $\begin{array}{c}\text { Absence } \\
(\mathrm{n}=49)\end{array}$ \\
\hline FR & $0.78 \pm 0.14$ & $0.83 \pm 0.27$ & $0.80 \pm 0.23$ & $0.80 \pm 0.22$ & $0.82 \pm 0.26$ & $0.80 \pm 0.22$ & $0.85 \pm 0.25$ & $0.79 \pm 0.22$ \\
UR & $0.97 \pm 0.05$ & $0.96 \pm 0.03$ & $0.98 \pm 0.04$ & $0.96 \pm 0.04$ & $0.97 \pm 0.03$ & $0.96 \pm 0.04$ & $0.96 \pm 0.04$ & $0.96 \pm 0.04$ \\
TUG & $0.75 \pm 0.25$ & $0.69 \pm 0.20$ & $0.60 \pm 0.20$ & $0.74 \pm 0.22$ & $0.70 \pm 0.23$ & $0.72 \pm 0.22$ & $0.70 \pm 0.20$ & $0.72 \pm 0.22$ \\
SWOC & $1.0 \pm 0.34$ & $0.94 \pm 0.36$ & $0.86 \pm 0.39$ & $0.98 \pm 0.34$ & $0.76 \pm 0.20^{\dagger}$ & $1.0 \pm 0.36^{\dagger}$ & $0.80 \pm 0.27$ & $0.99 \pm 0.36$ \\
\hline
\end{tabular}

*In order to compare the judgment error ratios of the four tasks, analysis was focused on the 58 subjects who were included in the analysis of judgment error for the FR.

$\uparrow$ ANOVA indicated a significant difference in judgement error ratio for the SWOC when compared according to the presence or absence of a history of falls in the past year $(\mathrm{p}<0.05)$.

FR: Functional Reach test; UR: upward reach test; TUG: Timed Up and Go test; SWOC: Standardized Walking Obstacle Course 
It is interesting to note that the community-dwelling elderly in this study consistently underrated their abilities in spatially predictive tasks and overrated their abilities in temporally predictive tasks. Since reaching movements are often required in ADL and visual cues were available to the subjects during the test, the spatially predictive tasks may have been easier to imagine than the temporally predictive tasks. For the tasks that the elderly subjects were asked to visualize themselves completing, they may have modestly predicted their own ability in order to avoid estimation failure. In addition, the spatially predictive tasks may have been affected not only by predictive capacity but also by "self-efficacy," leading to underestimation of ability. Furthermore, the temporally predictive tasks might have been more challenging for the elderly because these kinds of tasks are seldom required in their ADL. Therefore, temporally predictive tasks might render more appropriate evaluations of judgment errors in the elderly than spatially predictive tasks.

Age was correlated with all of the measured variables in the present study except UR. Grip strength, score of trunk flexion in the long sitting, duration of the single-leg standing test with open/closed eyes, score of the FR, and the comfortable and maximum gait speeds all decreased with age, and times needed to complete the TUG and SWOC increased with age. Although the observed values of the FR, TUG, and SWOC correlated with age, neither judgment error nor absolute judgment error correlated with age. Thus, while a definite proportion of the elderly subjects made significant judgment errors, the errors did not necessarily increase or decrease overall with age. We divided the subjects into three age groups and compared judgment errors and absolute judgment errors. There were significant differences in absolute judgment error for the SWOC between the different age groups, though judgment error did not necessarily show a specific tendency toward either underestimation or overestimation with age. In other words, the judgment error trends do not seem to shift in one general direction with age. According to the factors other than age, it seemed that some elderly subjects underrated their own abilities and that others overrated them. There appeared to be a large margin of judgment error for the SWOC in older people. Since the absolute judgment error for the SWOC among subjects in their $80 \mathrm{~s}$ was higher than that among subjects in their $60 \mathrm{~s}$, subjects over the age of 80 were more likely to either underestimate or overestimate their abilities. Judgment error may also be affected by factors other than age, such as self-efficacy, degree of physical activity, or decreased physical strength. Further studies are needed.

In order to assess the characteristics of the four predictive tasks, we compared the judgment error ratios of each task. Our results indicated that there was a significant difference in the judgment error ratios among the four predictive tasks. It appeared that UR and the SWOC were easier to imagine than the FR and TUG. If judgment errors were also found in relatively easily imagined tasks, this result might be meaningful. However, the relationship between the level of task difficulty and judgment errors remains to be clarified. Hence, we compared four judgment error ratios from the perspectives of age (youngold vs. old-old), fear of falling, one-year retrospective falls incidence, and the possible risk of frailty. A significant difference was found only in the judgment error ratio for the SWOC in association with the one-year retrospective incidence of falls. This finding may be because of the distinct characteristics of the temporally predictive tasks, that is, the TUG and SWOC; ultimately, the SWOC may be a better test to evaluate judgment errors in the elderly.

The judgment errors in the community-dwelling elderly people were revealed by both the spatially predictive and temporally predictive tasks. In general, the elderly participants tended to underrate their own abilities in spatially predictive tasks and overrate them in the temporally predictive tasks. Temporally predictive tasks might be superior to spatially predictive tasks in terms of evaluating judgment errors in the elderly. In particular, the SWOC might be more useful that the other predictive tasks we used for evaluation.

One of the limitations of this study is that we did not have a control group of young people. In addition, we need to better understand how subjects visualize their performance during temporally predictive tasks by using of the mental chronometry method, since visualization (first-person or third-person visualization) also affects judgment error. Furthermore, we need to study the relationship between an individual's tendency to overestimate or underestimate his/her own abilities and fall risk. This will require a larger sample size in a future study.

\section{REFERENCES}

1) Tinetti ME: Factors associated with serious injury during falls by ambulatory nursing home residents. J Am Geriatr Soc, 1987, 35: 644-648. [Medline] [CrossRef]

2) Tinetti ME, Speechley M, Ginter SF: Risk factors for falls among elderly persons living in the community. N Engl J Med, 1988, 319: 1701-1707. [Medline] [CrossRef]

3) Morfitt JM: Falls in old people at home: intrinsic versus environmental factors in causation. Public Health, 1983, 97: 115-120. [Medline] [CrossRef]

4) Niino N: Gait disturbance/ Falls. Clin All-Round, 2003, 52: 2121-2125 (in Japanese).

5) Niino N, Kozakai R, Eto M: [Epidemiology of falls among community-dwelling elderly people]. Nippon Ronen Igakkai Zasshi, 2003, 40: 484-486 (in Japanese). [Medline] [CrossRef]

6) Berg WP, Alessio HM, Mills EM, et al.: Circumstances and consequences of falls in independent community-dwelling older adults. Age Ageing, 1997, 26: 261-268. [Medline] [CrossRef]

7) Lipsitz LA, Jonsson PV, Kelley MM, et al.: Causes and correlates of recurrent falls in ambulatory frail elderly. J Gerontol, 1991, 46: M114-M122. [Medline] [CrossRef]

8) Yasumura S, Haga H, Nagai H, et al.: [Incidence of and circumstances related to falls among the elderly in a Japanese community]. Nippon Koshu Eisei Zasshi, 
1991, 38: 735-742 (in Japanese). [Medline]

9) Sugihara T, Mishima S, Tanaka M, et al.: Physical ability estimation and falling in the elderly. J Phys Ther Sci, 2006, 18: 137-141. [CrossRef]

10) Okada Y, Takatori K, Nagino K, et al.: Relationship between in estimated reach distance and falls in community-dwelling elderly people. J Jpn Phys Ther Assoc, 2008, 35: 279-284 (in Japanese).

11) Chang D, Huo M, Maruyama H: Cognitive ability of elderly people of an object height and exercise time-comparison with the young-. Rigakuryoho Kagaku, 2007, 22: 287-292 (In Japanese). [CrossRef]

12) Sugihara T, Mishima S, Tanaka M, et al.: Self-awareness of physical ability and falling in the elderly. Annu Rep Tohoku Sect Jpn Phys Ther Assoc, 2006, 18 : 29-33 (in Japanese).

13) Sugihara T, Go T, Mishima S, et al.: Elderly people's physical strength awareness and falling. Rigakuryoho Kagaku, 2005, 20: 13-16 (in Japanese). [CrossRef]

14) Robinovitch SN: Perception of postural limits during reaching. J Mot Behav, 1998, 30: 352-358. [Medline] [CrossRef]

15) Yamada M, Furukawa H, Higashino E, et al.: Motor imagery for walking is associated with fall in elderly people. Gen Rehabil, 2007, 35: 705-710 (Sogo Rehabilitation) (in Japanese).

16) Beauchet $\mathrm{O}$, Annweiler C, Assal F, et al.: Imagined Timed Up \& Go test: a new tool to assess higher-level gait and balance disorders in older adults? J Neurol Sci, 2010, 294: 102-106. [Medline] [CrossRef]

17) Ogawa M, Miyaguchi H, Kinoshita H, et al.: Relationship between falling and the difference between motor prediction and actual motor performance among elderly people. Gen Rehabil, 2009, 37: 339-346 (Sogo Rehabilitation) (in Japanese).

18) Liu-Ambrose T, Ahamed Y, Graf P, et al.: Older fallers with poor working memory overestimate their postural limits. Arch Phys Med Rehabil, 2008, 89: 1335-1340. [Medline] [CrossRef]

19) Sakurai R, Fujiwara Y, Ishihara M, et al.: Age-related self-overestimation of step-over ability in healthy older adults and its relationship to fall risk. BMC Geriatr, 2013, 13: 44. [Medline] [CrossRef]

20) Robinovitch SN, Cronin T: Perception of postural limits in elderly nursing home and day care participants. J Gerontol A Biol Sci Med Sci, 1999, 54: B124B130, discussion B131. [Medline] [CrossRef]

21) Duncan PW, Weiner DK, Chandler J, et al.: Functional reach: a new clinical measure of balance. J Gerontol, 1990, 45: M192-M197. [Medline] [CrossRef]

22) Podsiadlo D, Richardson S: The timed “Up \& Go": a test of basic functional mobility for frail elderly persons. J Am Geriatr Soc, 1991, 39: 142-148. [Medline] [CrossRef]

23) Taylor MJ, Gunther J: Standardized walking obstacle course; preliminary reliability and validity of a functional measurement tool. J Rehabil Outcomes Meas, 1998, 2: 15-25.

24) Decety J, Jeannerod M, Prablanc C: The timing of mentally represented actions. Behav Brain Res, 1989, 34: 35-42. [Medline] [CrossRef]

25) Matsuo A, Morioka S, Hiyamizu M, et al.: Temporal congruence of motor imagery in young subjects. Jpn J Neuropsychol, 2006, 22: 153-156 (in Japanese).

26) Gibson M, Andres R, Isaacs B, et al.: The prevention of falls in later life. A report of the Kellogg International work group on the prevention of falls by the elderly. Dan Med Bull, 1987, 34: 1-24. [Medline]

27) Suzuki T, Sugiura M, Furuna T, et al.: [Association of physical performance and falls among the community elderly in Japan in a five year follow-up study]. Nippon Ronen Igakkai Zasshi, 1999, 36: 472-478 (in Japanese). [Medline] [CrossRef]

28) The Japanese Ministry of Education: Culture, Sports, Science and Technology (MEXT). Physical Fitness and Athletic Ability Survey in 2011. http://www. mext.go.jp/b_menu/toukei/chousa04/tairyoku/kekka/k_detail/1326589.htm (in Japanese) (Accessed Apr. 14, 2016)

29) Niino N: Falls. Geriatr Med, 1998, 36: 849-853 (in Japanese).

30) Sugihara T, Go T: Self-cognition of physical strength among elderly people. J Jpn Acad Health Sci, 2005, 7: 257-261 (in Japanese). 